\title{
Recent Trends in the Use of Bioceramics for Treatment of Osteomyelitis
}

\author{
Noha H. Radwan", Maha Nasr, Rania A.H. Ishak, Gehanne A.S. Awad \\ Department of Pharmaceutics and Industrial Pharmacy, Faculty of Pharmacy, Ain Shams University, Cairo 11566, \\ Egypt
}

\begin{abstract}
Despite the inherent ability of bone for self-repair, this spontaneous healing capability in some bone disorders is not sufficient. Diseases as osteomyelitis, osteosarcoma, and osteoporosis, usually demand medical and/or surgical interventions to enhance tissue regeneration, control infection or to handle the clinical condition. Osteomyelitis (OM) is a bone infection disease, where Staphylococcus $(S$.) aureus is the main causative microorganism. OM is characterized by elevated rates of relapse and mortality. Coupling local osseous delivery of antibacterial agents with bioactive agents capable of bone regeneration was intensely studied for the treatment of OM, proving their effectiveness. Bioceramics are widely investigated due to their osteoconductive and osteointegration nature. Among these are calcium phosphates (CP), which are distinguished by a similar structure to that of bones and diverse resorption rates. $\mathrm{CP}$ is applied in the bone regeneration field, either solely or as composites with different polymers, as scaffolds, pastes, cement, and hydrogels. In this review we overview OM disease with its pathogenesis and treatment, especially focusing on different CP-bioceramics used for bone repair.
\end{abstract}

Keywords: Osteomyelitis; Calcium phosphate; Bioceramics; Scaffolds; Composites.

*Correspondence | Noha H. Radwan; Department of Pharmaceutics and Industrial Pharmacy, Faculty of Pharmacy, Ain Shams University, Cairo 11566, Egypt. Email: noha.hesham@pharma.asu.edu.eg

Citation | Radwan NH, Nasr M, Ishak RA, Awad G, 2020. Recent trends in the use of bioceramics for treatment of osteomyelitis. Arch Pharm

Sci ASU 4(1): 1-19

DOI: $10.21608 /$ APS.2020.2001.1021

Print ISSN: 2356-8380. Online ISSN: 2356-8399.

Received 09 January 2020. Accepted 17 February 2020.

Copyright: ${ }^{{ }_{2}} 2020$ Radwan et al. This is an open-access article licensed under a Creative Commons Attribution 4.0 International License (CC BY 4.0), which permits unrestricted use, distribution, and reproduction in any medium, provided the original author(s) and source are credited.

Published by: Ain Shams University, Faculty of Pharmacy

\section{INTRODUCTION}

Bone is a type of connective tissue in the higher vertebrates, characterized by its mineral architecture [1, 2]. Being hard, it is responsible for locomotion, support and soft tissue conservation as well as storage of calcium and phosphate, and holding the bone marrow [2]. Bone frequently undergoes remodeling which is an active process, where old bone is resorbed by osteoclasts and new bone is formed by osteoblasts $[3,2]$. This regular bone remodeling which occurs through harmony between bone cells namely; osteoclasts, osteoblasts, osteocytes and lining cells, is essential for fissures healing, compliance of skeleton for mechanical benefits and calcium equilibrium in the body $[4,2]$. Any disturbance of the normal bone remodeling process leads to bone diseases such as osteoporosis and osteopetrosis, also known as marble bone disease or "stone bone" [2].

The basic framework of bones is comprised of outer cortical bones and inner trabecular bone 
tissues, as illustrated in Fig. 1 [3, 5, 6]. Cortical bones are compact, surround the bone marrow and the trabecular plates and are developed from the Haversian system. The latter is comprised of concentric lamellae encompassing blood vessels harbored in a medial canal. The spongy trabecular tissues form a grid with a honeycomblike structure composed of trabecular plates and rods, which are dispersed throughout the marrow cavities $[\mathbf{1}, \mathbf{3}, \mathbf{5}]$.

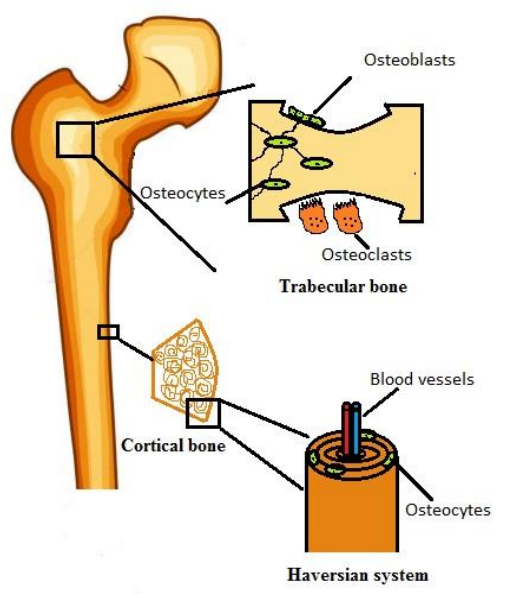

Fig. 1. Structure of bone

Bone diseases involve several skeletalrelevant disorders that can cause mobility difficulties to deaths along with time [7]. The most common bone disorders are osteoporosis, osteoarthritis, osteosarcoma, metastatic bone cancer, osteomyelitis, and bone degenerative disorders [7, 8]. In bone defects management, surgery and bone tissue engineering are the most applied techniques with the local or targeted delivery of drugs, growth or bioactive factors [7, 8].

\section{Osteomyelitis (OM)}

$\mathrm{OM}$ is a grievous infectious disease of the bones, characterized by progressive destruction of the bone, associated with high recurrence rate, morbidity and high treatment cost $[9,10]$. The infection can include one part of the osseous tissues or extend to other sites as the bone marrow, cortex, periosteum or the neighboring soft tissues [9]. Several microbes can induce OM; the most predominant microorganism is ( $S$. aureus) accounting for $90 \%$ of the cases $[11,12]$. Other microbes include Pseudomonas aeruginosa, Candida species, Mycobacterium tuberculosis, Brucella species, and others $[9,13$, 14].

S. aureus has a powerful adaptive competency and discharges virulence factors that alter the host immune response $[\mathbf{1 5}, \mathbf{1 0}]$. This bacterium is characterized by biofilm formation which is the leading reason for developing bacterial resistance [16]. It releases adhesive components on its surface that advocate attachment to bone extracellular matrix proteins as fibronectin, fibrinogen, collagen, bone sialoprotein, elastin, and others $[9,17,12]$. Additionally, it can invade viable cortical bone cells resulting in biofilm deposition inside osseous lacunae [12].

\subsection{OM Classification}

OM can be classified in several ways based on; the chronicity (whether acute or chronic), the etiology of the disease (either due to hematogenous migration of the causative organism, contiguous spread following injury or trauma or secondary to vascular or neurologic insufficiency) according to Waldvogel classification, and the anatomic factors combined with the physiological classes (Cierny-Mader classification) [13]. The latter classification helps to stratify the basic elements for treatment according to the magnitude of bone necrosis, the patient's condition and the influence of $\mathrm{OM}$ on body functions $[18,19]$.

\subsection{Pathogenesis of $\mathrm{OM}$}

Bones are normally resistant to infection due to the unique physiological and anatomic features. When an infection reaches the bone, a series of inflammatory processes occur due to 
inflammatory factors and leukocytes migration leading eventually to necrosis of bone tissues. The ischemia accompanying the inflammatory processes leads to compressed and destroyed vascularity, that in turn ends with necrotic bone tissues called sequestra [13]. These sectors of bones deprived of vascular supply can carry bacteria and pus despite antibacterial treatment [17]. Due to the active hyperemia on the infarction boundary, inflammatory cells and their cytokines provoke bone resorption by osteoclasts and fibrous tissue growth with new bone deposition on the damaged periosteum [20, 21]. This new osseous tissue surrounding the necrotic infected sequestrum is termed involucrum. The pathogenesis of $\mathrm{OM}$ is divided into three stages, as illustrated in Fig. 2.

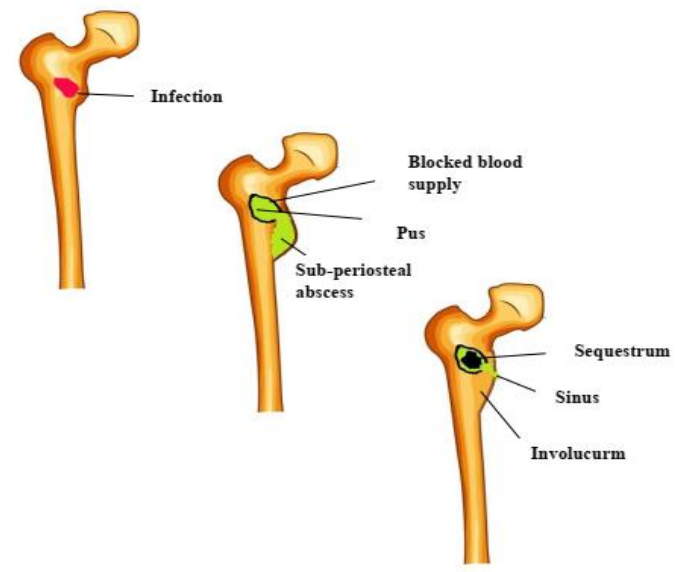

Fig. 2. Pathogenesis of OM (Stages I, II, and III)

Stage 1 represents the invasion of the medullary canal by the causative pathogen forming infection foci. Stage 2 is considered the acute phase, where pus is formed from the infected abscess due to the host inflammatory reactions with a spread to the vessels. Stage 3 follows the chronic phase, where the obliteration of vasculature leads to ischemia that eventually leads to bone necrosis and development of sequestrum [20, 21, 17].

\subsection{Treatment of $\mathrm{OM}$}

In most cases, the treatment of chronic OM necessitates the combination of surgical intervention and systemic antibiotic administration [14]. Sufficient debridement of necrotic tissues and sinus tracts by surgery is a keystone for efficient treatment. Surgery has vital roles other than the removal of necrotic osseous tissues, these include the abolition of dead spaces left after the debridement of necrosis, osseous stabilization and covering of soft tissues [14]. As in oncology, conservative and provincial abscission is accompanied by high relapse rates $[9,14]$. Hence, the removal of the entire necrotic infected tissues and biofilm and assuring sufficient blood supply preliminary to medical therapy is mandatory [14]. This is followed by systemic administration of antibiotics for an extended time course; most probably 4 to 6 weeks of intravenous administration is the standard for $\mathrm{OM}$ treatment. However, some clinicians suggest longer courses for eight weeks followed by oral antibiotic therapy for three months in cases of high relapse and recurrence rates [14].

A major pitfall is that the systemic delivery of antibiotics hinders their efficacy owing to firstpass metabolism and their distribution to different body organs, hence, only a small fraction can hit the infection site [22]. Moreover, in the case of OM, the demolition of the local vascular supply makes it more strenuous for the antibacterial agents to reach their target site [22]. The systemic toxicity associated with high levels of antibiotics in the body as hepatotoxicity and nephrotoxicity, along with the emerging crisis of bacterial resistance; limit increasing the dosage of the given antibiotic to compensate for the low drug levels at the infection spot [23, 24]. So, it is believed that the local delivery of antibiotics is beneficial for delivering sufficient concentration of the antibiotic at the bone tissues with low 
blood concentration levels [25]. Different systems for antibacterial delivery for the treatment of $\mathrm{OM}$ are illustrated in Fig. 3.

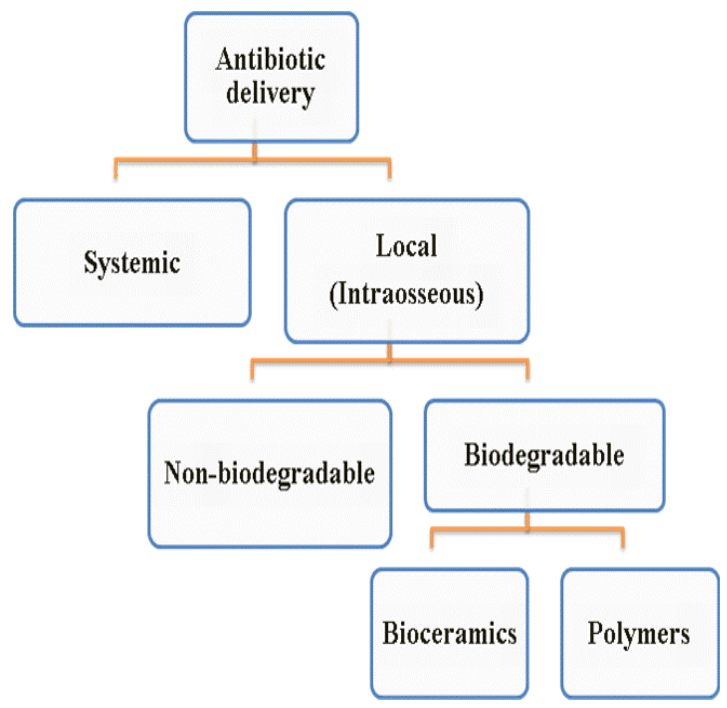

Fig. 3. Different systems for antibiotic delivery for treatment of OM.

\subsection{Local osseous delivery}

Local drug delivery was primarily introduced to restrain bone infection in the sixties through "closed irrigation" of antibiotic solutions [26]. Nowadays, bone fillers loaded with actives are extensively employed to deliver drugs intraosseously. The optimum bone filler should be able to deliver its loaded antibiotic locally with a controlled release profile and to aid bone growth to restore the osseous cavities left after the debridement of necrotic tissues.

Ideally, the perfect bone scaffold for tissue repair should provide a suitable network with adequate porosity permitting vascularization and new bone cell penetration and growth. Besides, it should be able to arbitrate osteoconduction, osteoinduction, osteointegration, and osteogenesis processes. Osteoconduction is the stimulation of new bone deposition by providing the optimum conditions and the skeleton for osteogenic and neoplastic cells adhesion and bone penetration. Osteoinduction is the stimulation of stem cell differentiation into osteoblasts that are capable of bone formation similar to bone morphogenetic proteins (BMP). Osteointegration is the attachment between native bone cells and the bone filler, with new cells gradually substituting the device as they grow. Finally, osteogenesis is the process of new bone synthesis [27, 28]. Another important aspect of the ideal bone scaffold is to degrade at a rate that matches the process of new bone growth to allow host cells to replace it, and to resorb with neither toxic byproducts nor inflammatory response [29].

\subsubsection{Non-degradable fillers}

Poly (methyl methacrylate) (PMMA) bone cement/beads bearing various antibiotics are used for local treatment of OM. They can release their loaded antibiotics slowly and act as bone fillers $[26,30]$. They are commonly used as they are the only approved pre-installed devices by the US Food and Drug Administration (FDA) [25]. However, PMMA is not clinically desirable as its polymerization reaction is exothermic producing heat [30, 25], and their remnant unreacted monomers are toxic [31, 30]. Thermolabile antibiotics are not suitable to be loaded on PMMA due to the high exothermic reaction temperature [32]. Besides, their loaded carriers fail to attain the sustained release required with only a small fraction of the loaded antibiotic being released, this may be due to the nonbiodegradability of the polymer which prohibits their release from the matrix core. After the initial burst release, the sub-inhibitory concentration of the antibacterial agent is released, causing the carrier itself to act as a surface where bacteria can thrive forming colonies and new biofilm further contributing to the development of bacterial resistance $[\mathbf{3 1}, \mathbf{2 5}$. Moreover, PMMA is deprived of the osteoconduction features so their attachment to bone cells is inadequate [31, 25]. Being nonbiodegradable, a second surgery is required for their elimination as their presence can hinder the 
new bone formation and regeneration process and may allow bacterial colonization on their surfaces $[32,22]$.

\subsubsection{Biodegradable fillers}

Biodegradable systems for local delivery of antibiotics are the focus of many researchers nowadays. They eliminate the need for a second surgery for their removal. Besides, being biodegradable they prevent the possibility of bacterial growth as in the case of bio surfaces $[33,27,22]$.

Biodegradable natural and synthetic polymers; chitosan (CS), collagen, poly-lactide, polylactide-co-glycolic and polycaprolactone, were used as resorbable implants for bone tissue regeneration [7]. Natural polymers display favorable biocompatibility and have been extensively investigated for drug delivery [34, $35,7]$. Collagen has been widely applied for bone generation applications as it is the principal component of the extracellular matrix (ECM) [34, 35]. Gelatin; derived from collagen by denaturation, is characterized by low immunogenic potential, good biocompatibility, safety and providing sustained release. It has been extensively applied in bone engineering [35]. Hyaluronic acid is a natural, biodegradable glycosaminoglycan molecule constituting one of the main components of ECM [36]. When applied in bone delivery, it enhances osseous growth and has a proven ability to alleviate bacterial attachment and biofilm production [34, 36]. Chitosan (CS) is a cationic polymer, obtained naturally from crustaceans by deacetylation of chitin [28]. It has excellent biocompatibility and biodegradability properties. It exhibits antibacterial, antitumor and hemostatic features [28, 37]. It has been widely studied for biomedical tissue engineering. When applied in bone repair application, it appeared to support bone tissue growth and regeneration [34].
Synthetic polymers can be facilely controlled in terms of their physicochemical, mechanical and bio-resorption rates [7]. For example, polylactide (PLA) is used in bone devices and implants due to its huge mechanical strength [38, 7]. Poly-lactide-co-glycolic (PLGA) is a polyester that is approved for bone repair applications by the FDA [7]. It has optimal biodegradation behavior with minimum inflammatory reaction stimulation [39]. Polycaprolactone (PCL) is extensively used in bone regeneration due to its attractive mechanical properties and manufacturability [37]. Polyurethane (PU) comprises a family of synthetic elastomers composed of soft segments of polyester chains and hard segments including mainly polyurethane blocks. They have good mechanical properties driving their use in biomedical devices. However, they suffer low biocompatibility due to their released toxic degradation products, which can be alleviated through creating chemical linkages that are broken in the biological conditions [40].

However, the use of polymeric scaffolds/cement alone is restricted due to their low mechanical strength and the inflammatory reaction produced by the acidic environment resulting from the degradation of some of the synthetic polymers. Hence, composites of ceramics with biodegradable polymers offer suitable osteoconductive and osteoinductive systems for efficient treatment of OM [7, 41].

\subsubsection{Bioceramics}

Ceramics are inorganic compounds with ionic and covalent bonds combination. Bioceramics are those proposed to be intermingled with viable tissues [42]. Bioceramics; as calcium phosphates, calcium sulfates, and bioactive glasses, has the merits of biocompatibility and the ease of recognition and acceptance by the body [43]. In bone regeneration and repair applications, bioceramics are considered favorable materials as 
they are capable of forming direct bonds that interact with the bone tissues [44]. They can enhance the mineralization of damaged bone tissue and implicate optimal osteoconductivity while offering protection against chemical corrosion [45].

Bioactive glasses are a group of biomaterials capable of repairing and regenerating impaired bone tissues with osteoconductive and bioactive attitudes [46, 47]. Their manufacturing techniques depend mainly on two methods; meltquenching and sol-gel methods [48, 49]. Upon contact with the physiological environment, they release calcium, phosphate and silica ions, which undergo steady crystallization leading to the construction of apatite that eventually induces bone regeneration [47]. Through biochemical transitions, they induce differentiation and replication of osteoblasts [45]. They are silicatebased biomaterials but recently more classes were established as phosphate-based and boratebased glasses [45]. However, they lack the required mechanical toughness for weightbearing support [46, 50, 47].

Calcium sulfate bioceramics have compressive strength equivalent to that of cancellous bone. It is found in the following forms, anhydrous $\left(\mathrm{CaSO}_{4}\right)$, hemihydrate $\left(\mathrm{CaSO}_{4} \cdot 0.5 \mathrm{H}_{2} \mathrm{O}\right)$ and dihydrate $\left(\mathrm{CaSO}_{4} \cdot 2 \mathrm{H}_{2} \mathrm{O}\right)$ which is known as "plaster of Paris". Calcium sulfate is efficient at emitting high levels of local antibiotic in the bone because it resorbs relatively quickly. On the other hand, the ceramic is brittle and rapidly loses its strength upon hydrolysis. Its resorption occurs somehow quickly; 3-6 weeks in soft tissues and 6-12 weeks in bone [51, 27, 52]. Since it does not last for enough time to support new bone healing, it is not effective as a structural void filler. So, it is unsuitable to supply significant long-term mechanical support or act as a scaffold for tissue regeneration [27].
Calcium phosphates (CP) are endogenous compounds in the human system having bonelike structure and are widely used in orthopedic and dentistry applications owing to their structure closeness to the mineral normal bones [45]. CP compounds used in bone grafting include monocalcium phosphate (MCP), dicalcium phosphate dihydrate (brushite, DCPD), alpha and beta-tricalcium phosphate ( $\alpha$-TCP and $\beta$-TCP), hydroxyapatite (HAp) and tetra calcium phosphate (TTCP) $[\mathbf{6}, \mathbf{4 5}]$. They can be arranged in terms of resorption rate as follows; $\alpha$-TCP > DCPD $>\beta-T C P>\operatorname{HAp}[\mathbf{5 3 , 4 5 ]}$. Tricalcium phosphate dissolves over a duration of time between 6-18 months [27], while monocalcium phosphate and hydroxyapatite can dissolve over a duration varying from 6 months to 10 years [51, 27]. So, a mixture of both can be used to enhance the implant features $[45,44]$.

$\mathrm{CP}$ compounds are utilized in different medical devices as cement, scaffolds, pastes, and coatings [6]. Calcium phosphate cement (CPCs) are a blend of one or more different CP powders, which upon adding a liquid they turn to selfsetting paste that can solidify in-situ forming bone scaffolds [54]. From the tissue engineering view, the scaffold is a framework capable of holding up new tissue growth in a 3D manner. Various CP scaffolds have been investigated, exhibiting optimal biodegradation and support to new bone cell growth [55].

However, CPCs are brittle in nature with inferior mechanical strength rendering them unsuitable in load-bearing applications $[\mathbf{2 7}, \mathbf{4 5}$, 56]. Owing to their deficient mechanical stability, $\mathrm{CP}$ can be fabricated as coatings on the metal substrate as Titanium (Ti) alloys or polymeric implants [42]. CP as a coating enormously enhances the overall properties of the implant by combining the bioactivity of the bioceramics and the good mechanical strength of the substrate [57]. 
$\mathrm{CP}$ bioceramic powders fabrication techniques are based on dry or wet chemical synthesis. Dry ones depend on reactions of the solid-state as redox reactions and thermal decomposition, while wet methods involve wet precipitation, solgel synthesis, hydrothermal synthesis, or spray drying [58, 45]. Wet precipitation technique is favorable as it produces a homogenous product, the processing parameters as temperature and $\mathrm{pH}$ can be controlled, and including additives during the synthesis is possible [58, 45]. Various CPbased systems are illustrated in Fig. 4.

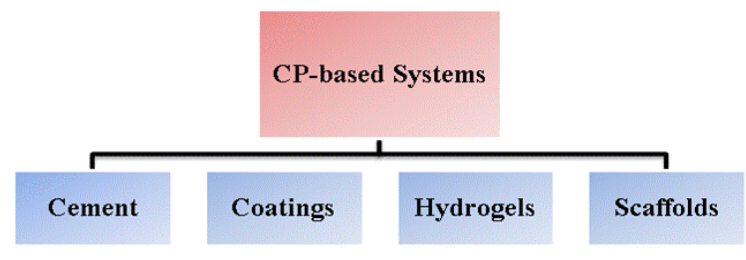

Fig. 4. Various CP-based systems

Several studies based on composites that can be loaded with drugs and/or growth factors for local osseous delivery and bone repair and regeneration applications were described in the literature.

\section{Various CP-based delivery systems}

\subsection{Calcium phosphate cements (CPCs)}

CPCs are settable forms of calcium phosphates; they can be used as bone fillers and tailored into customized shapes according to the defect [59, 60]. They are CP powder, that upon admixing with the proper liquid they turn into a paste [59]. These pastes can be injected into the defect site and harden after implantation offering biocompatibility and osteoconduction to the bone defect [22].

Joosten et al. prepared gentamicin loaded CPC by mixing commercially available HAp cement with different concentrations of gentamicin. The prepared in situ setting cement was evaluated by in vitro and in vivo studies. Increasing gentamicin concentration had a non- significant effect on the compressive strength of the cement. The prepared cement showed promising results for the local treatment of OM [61].

Stallmann et al. studied the efficacy of CPC loaded with the polypeptide antimicrobial human lactoferrin 1-11 (hLF1-11) or with gentamicin for prophylaxis of $\mathrm{OM}$ in rabbits [62]. After the inoculation of $S$. aureus into the femur, the loaded CPC was injected into the femoral canal. Their results showed a significant reduction of bacterial growth with bone ingrowth within the CPC [60].

Huang et al. prepared a dual drug delivery system containing vancomycin and icariin (a flavonoid with a pronounced positive effect on osteoblast proliferation) loaded on CPC. This injectable system was prepared by mixing vancomycin $\mathrm{HCl}$ solution and icariin solution with the commercial CPC powder. After three months of implantation, the infected osseous defects revealed no significant infection with marked new bone formation [63].

Mestres et al. studied the efficacy of OM eradication of calcium phosphate cement (microporous) and calcium phosphate foams (macroporous), as unloaded and doxycycline Hyclate-loaded systems, and unloaded magnesium phosphate cement (MPC). The loaded macroporous CPC and MPC with its antimicrobial activity exhibited optimum eradication of bacteria in animals. These promising results with the osteoconductive effect of CPC delineate them as promising systems for the treatment of OM [22].

\subsection{Calcium phosphate-based coatings}

Calcium phosphate-based coatings were developed to enhance the implant osteointegration, bonding, and fixation into the osseous tissues [58, 45, 64]. The principal techniques used for deposition of $\mathrm{CP}$ coatings 
onto implants are; plasma-spraying, thermal evaporation and biomimetic co-precipitation [65, 57].

Stigter et al. applied a carbonated hydroxyapatite coating on titanium alloys through the biomimetic precipitation method. They incorporated different antibiotics into the coatings and assessed their release and antibacterial efficiency through in vitro studies, assuming that the biomimetic precipitation technique was favorable for drug incorporation within the coatings rather than the plasmaspraying technique, as the latter includes high temperature during processing. They concluded that the release of drugs incorporated into the coatings depends on the porosity and permeability of the coating and the chemical structure and binding of the drug with the coating [65].

Neut et al. investigated the efficacy of gentamicin loaded-HAp coating with PLGA overlayer onto Ti-alloy in the prevention of bacterial colonization on the cementless orthopedic prostheses through inoculation of bacteria before the operation. They conducted in vitro and in vivo studies to investigate the efficacy in bacterial elimination and bone ingrowth enhancement. Their results suggested the use of PLGA-gentamicin-HAp coating as an effective tool for prophylaxis of infection on cementless orthopedic prostheses [66].

Thompson et al. studied the efficacy of gentamicin loaded on CP coating to protect against orthopedic device-related infections (ODRI). The implant used in this study was CPcoated titanium aluminum niobium (TAN) discs. They proposed intraoperative loading of gentamicin by dipping CP-coated TAN discs into a solution of gentamicin. Gentamicin showed a burst release of about $95 \%$ with $15 \mathrm{~min}$. In vivo testing showed the efficacy of loaded gentamicin in the prevention of ODRI and recommended its use for the prevention of $S$. aureus infection in bone surgeries [64].

PCL loaded HAp and rifampicin were applied on Ti implant as a coating by Kranthi Kiran et al. Their results showed that the presence of HAp increased the tensile strength of the scaffold. To assess the cytocompatibility of the scaffolds, MTT assay was carried out on human fetal osteoblast cells (hFOB) and proliferation and adhesion of scaffolds on cells were determined. Their findings indicated the positive biocompatibility of scaffolds with improved cell proliferation. Initial burst release followed by a gradual release of rifampicin with significant antibacterial activity was reported [67].

\subsection{Hydrogels containing $\mathrm{CP}$}

Hydrogels are gels formed from networks of 3D hydrophilic crosslinked polymers. Being highly hydrophilic, they can absorb enormous amounts of water imparting excellent mechanical strength and outstanding cell growth support. They can simulate ECM and allow the transport of oxygen and nutrients $[68,48]$. The injectable capability of hydrogels renders them beneficial in reducing invasive intervention and improving patient compliance. Besides, they are capable of mold in situ to fit irregular bone defects $[69,48]$. Owing to their network structure, bioactive molecules and drugs can be entrapped within their matrix and released in a controlled manner [68, 70]. To impart osteoconductivity to injectable hydrogels, bioceramics can be incorporated within their networks improving their mechanical strength as well [48].

Zheng et al. fabricated an implant of HAp/PLGA composite scaffold containing hydrogel of PLGA-PEG-PLGA triblock loaded with platelet-rich fibrin (PRF), rich in growth factors. This hydrogel-scaffold system allowed for improved adhesion and proliferation on MG63 osteoblast-like cells and is suggested to be 
useful in bone repair applications [71].

Dhivya et al. developed a thermosensitive zinc-doped chitosan/nanohydroxyapatite/ $\beta$ glycerophosphate hydrogel for osseous regeneration. They proved that HAp imparted osteoconductive features to the system. Due to its antimicrobial activity, zinc had a significant role in the in vitro antibacterial testing calculated through inhibition zones. Their findings showed that the hydrogel is osteoconductive, stimulated mouse mesenchymal stem cells differentiation to osteoblasts, and enhanced bone healing in the tibial defect in rats in vivo [72,73].

\subsection{Ceramic-composite scaffolds}

Owing to the composite nature of bones, it is relevant to develop composite scaffolds to achieve superior bioactivity and biomimicry in bone applications [48]. The bioactivity properties of scaffolds can be improved by the incorporation of materials capable of interaction with or attachment to viable tissues. This can subsequently enhance the osteoconductive function by inducing bone cell growth, augmenting osteointegration and fixation of the scaffold within osseous tissues, and boosting vascularization [48]. An ideal scaffold should be biocompatible, biodegradable, of matching mechanical strength to the bones, its resorption rate should match the rate of new cell growth, to be replaced by host native cells. Also, a scaffold with an optimal microarchitecture would allow the exchange of oxygen and nutrients and help cell migration through its interconnected porous structure $[\mathbf{7 4}, \mathbf{7 5}, \mathbf{4 8}]$. Fabrication techniques for scaffolds include solvent casting/particulate leaching, gas foaming, emulsification freezedrying, phase separation, electrospinning, and 3D printing techniques [48]. A brief on previous studies in the literature on ceramic composite scaffolds for localized treatment of $\mathrm{OM}$ is summarized in Table 1.

\subsection{Other intra-osseous delivery systems}

Yong et al. fabricated biphasic BTCP/carbonate apatite scaffold coated with sodium alginate. The highest mechanical strength of the scaffold was obtained with a 5\% concentration of sodium alginate [93].

Sasireka et al. developed a composite coating of ciprofloxacin (CIP) with plasma polymerized ethylenediamine/ $\mathrm{TiO}_{2}-\mathrm{SiO}_{2}$ on Titanium alloy which exhibited optimum resistance to corrosion, better antibacterial activity, and favorable cell adhesion and proliferation on L929 fibroblasts [43].

Pawar and Srivastava developed polymeric blend sponge composed of CS and PCL in different ratios that were further loaded with ibuprofen and CIP for the treatment of chronic OM. The sponge with a $75 \mathrm{CS} / 25$ PCL ratio demonstrated optimal drug release profile with accepted antibacterial and anti-inflammatory efficacy rendering the sponge a promising candidate for OM treatment [37].

Based on the aforementioned overview of the different systems for the treatment of osteomyelitis, the biodegradable bone fillers are optimum for the local intraosseous delivery and bone repair purposes. Among these are $\mathrm{CP}$, which we thought to be the favorable bioceramics due to their structural similarity to native bones and optimum resorption rate. However, these should be coupled with polymers to enhance their mechanical strength for load-bearing applications.

\section{Conclusion}

$\mathrm{OM}$ is a difficult-to-treat disease, where surgical debridement of necrotic tissue with long term antibiotic therapy is demanded. Local osseous delivery of antibiotics coupled with bone regenerative therapy is always advantageous. Biodegradable bone substitutes are favorable 
over their counterparts, due to their osteoconductive and osteointegration nature. $\mathrm{CP}$ is widely applied as bone fillers as cement, pastes, hydrogels, coating or scaffolds, either alone or with polymers as composites. CP composites are distinguished with appropriate mechanical strength and resorption time. Loading of antibacterial agents with $\mathrm{CP}$ composites provide a proper solution for controlling local infection in bone tissues while replacing damaged osseous tissues with new ones.

Table 1. Different ceramic composite scaffolds for local treatment of OM in literature

\begin{tabular}{|c|c|c|c|c|}
\hline Polymer & Ceramic & $\begin{array}{l}\text { Active } \\
\text { moiety }\end{array}$ & Main findings & Reference \\
\hline 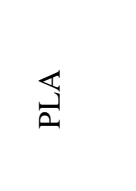 & 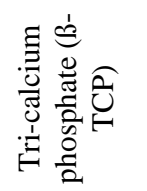 & 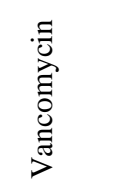 & $\begin{array}{l}\text { - Vancomycin-containing PLA/ B-TCP composites were able to control } \\
\text { antibiotic release and stimulate bone formation. } \\
\text { - The in vitro experiments showed an antibiotic release in the inhibitory doses } \\
\text { and biocompatibility based on cell culture studies of adhesion, proliferation, } \\
\text { and mineralization. }\end{array}$ & [76] \\
\hline 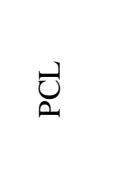 & 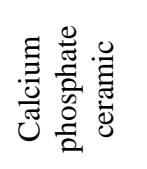 & 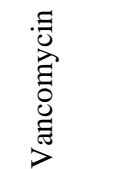 & $\begin{array}{l}\text { - Osteoconductive degradable composite loaded with vancomycin were } \\
\text { successfully prepared. } \\
\text { - The results delineate the system for local antibiotic therapy of osteomyelitis } \\
\text { and other bone infections. }\end{array}$ & [33] \\
\hline$\underset{\Xi}{త}$ & 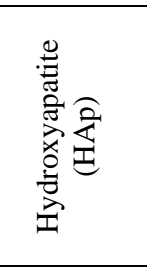 & 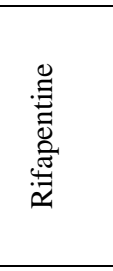 & $\begin{array}{l}\text { - A carrier of bone-like HAp/polyamine acid for PLGA-coated rifapentine } \\
\text { microspheres was developed. } \\
\text { - The in vitro experiments showed significant inhibition zones of } S \text {. aureus } \\
\text { bacterial colonies in inhibition assays as they achieved enhanced adhesion, } \\
\text { proliferation and calcium production on osteoblast-like cells (MG-63 cell line). } \\
\text { - The in vivo study showed significant control on bacterial growth and improved } \\
\text { bone healing and new bone formation in the infected animals. }\end{array}$ & [77] \\
\hline 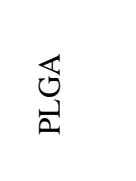 & 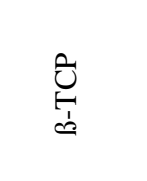 & 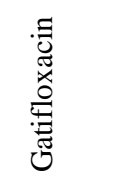 & $\begin{array}{l}\text { - The composites of gatifloxacin-loaded PLGA and B-TCP were proven to be } \\
\text { effective for the local treatment of osteomyelitis. }\end{array}$ & [78] \\
\hline \multirow{2}{*}{ 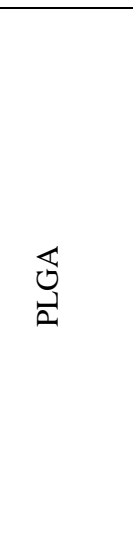 } & \multirow{2}{*}{ 宅 } & \multirow{2}{*}{ 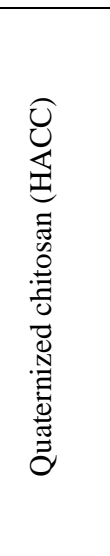 } & $\begin{array}{l}\text { - PLGA/HAp/HACC composite scaffold was fabricated using a 3D printing } \\
\text { method. } \\
\text { - The developed scaffold proved to have optimum antibacterial activity in vitro } \\
\text { and inhibited adhesion of bacteria and biofilm formation on scaffolds } \\
\text { implanted subcutaneously in rats. } \\
\text { - They promoted cell proliferation, adhesion, and differentiation of human bone- } \\
\text { marrow-derived mesenchymal cells while in-vivo biocompatibility test they } \\
\text { showed great neovascularization and integration in rats' tissues. }\end{array}$ & [79] \\
\hline & & & $\begin{array}{l}\text { - PLGA/HAp/HACC composite scaffolds were investigated in-vivo to assess } \\
\text { their capability of regeneration of infected bones in rabbits with induced bone } \\
\text { infections. } \\
\text { - The antibacterial and bone repair efficacy was determined through } \\
\text { radiographic, microbiological and histopathological evaluations. } \\
\text { - The composite scaffolds showed optimum in vivo results which impose the } \\
\text { system to be a model for local treatment of bone infections. }\end{array}$ & {$[80]$} \\
\hline
\end{tabular}




\begin{tabular}{|c|c|c|c|c|}
\hline Polymer & Ceramic & $\begin{array}{l}\text { Active } \\
\text { moiety }\end{array}$ & Main findings & Reference \\
\hline 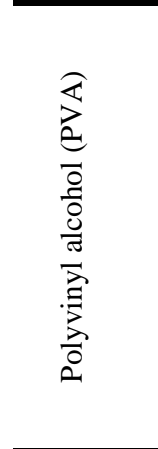 & 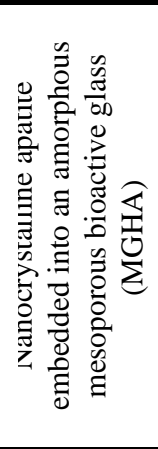 & 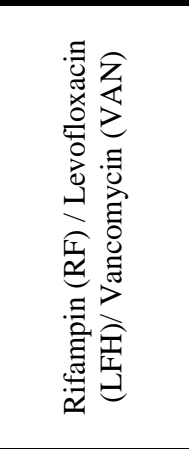 & $\begin{array}{l}\text { - MGHA nanocomposite/ PVA scaffold was developed with rapid prototyping } \\
\text { and coated externally with gelatin-glutaraldehyde. } \\
\text { - Each drug was loaded in different sites in the scaffold yielding different } \\
\text { kinetics of release and effective combined therapy: LFH was loaded into the } \\
\text { bioceramic part, VAN loaded into PVA while RF loaded into the outer } \\
\text { coating. } \\
\text { - The multidrug loaded scaffolds achieved the destruction of bacterial biofilm } \\
\text { that was detected by confocal laser scanning microscopy. } \\
\text { - They achieved optimum proliferation, differentiation, and mineralization of } \\
\text { MC3T3-E1 cells. } \\
\text { - The 3D multidrug loaded scaffold offered a promising tool for local treatment } \\
\text { of bone infections. }\end{array}$ & {$[81]$} \\
\hline 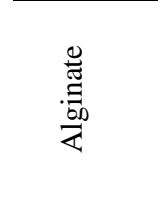 & 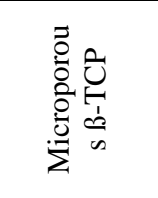 & 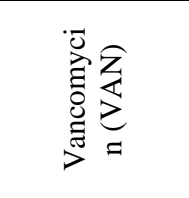 & $\begin{array}{l}\text { - The microporous } B \text {-TCP/ alginate composite had an interconnected porous } \\
\text { structure with } 40 \% \text { porosity. } \\
\text { - The composite showed antimicrobial activity against } S \text {. aureus. } \\
\text { - In vitro cytocompatibility on MG- } 63 \text { cells showed that the porous scaffold } \\
\text { increased the number of viable cells. }\end{array}$ & [82] \\
\hline 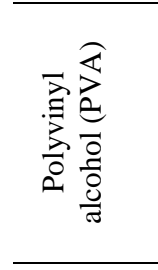 & $\underset{\circlearrowright}{0}$ & 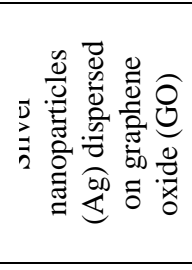 & $\begin{array}{l}\text { - } 3 \text {-TCP/PVA scaffold was fabricated by } 3 \mathrm{D} \text { printing technique wile } \mathrm{Ag} / \mathrm{GO} \\
\text { nanocomposite was synthesized in situ while preparation of } \mathrm{Ag} / \mathrm{GO} \text { modified } \\
\text { B-TCP scaffold was accomplished by simple soaking technique. } \\
\text { - The scaffold showed antimicrobial activity against E. coli owing to } \mathrm{Ag} \\
\text { presence. } \\
\text { - The scaffold exhibited good osteogenic behavior on rabbit-bone-marrow } \\
\text { stromal cells with an elevated level of ALP activity and cell attachment. }\end{array}$ & {$[83]$} \\
\hline 青市苇 & 斑 & 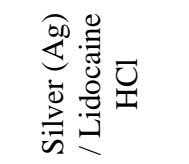 & $\begin{array}{l}\text { - The porous scaffold was fabricated by wet precipitation technique with } \\
\text { sustained release of Ag. } \\
\text { - This system provided an antibacterial activity for about } 360 \text { days and local } \\
\text { anesthesia for } 2 \text { weeks. }\end{array}$ & [84] \\
\hline $\begin{array}{l}\frac{0}{0} \\
\frac{0}{0} \\
\frac{\pi}{0} \\
.00 \\
0\end{array}$ & 空 & 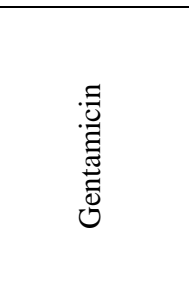 & $\begin{array}{l}\text { - Oligolactide-HAp porous scaffolds were fabricated using the } \\
\text { stereolithographic method and coated with gentamicin. } \\
\text { - The composite scaffold had a well-structured interconnected porous } \\
\text { framework. } \\
\text { - The released gentamicin levels over } 2 \text { weeks were higher than the minimum } \\
\text { inhibitory concentration of } S \text {. aureus and E.coli. } \\
\text { - The findings suggest the potential use of scaffolds for the prevention of } \\
\text { osseous infections. }\end{array}$ & {$[85]$} \\
\hline 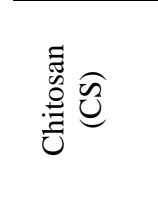 & 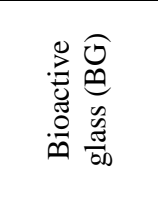 & 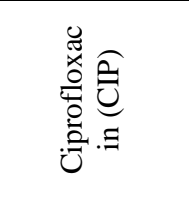 & $\begin{array}{l}\text { - CS scaffolds with or without BG was fabricated with the freeze-drying } \\
\text { technique, the selected scaffolds were loaded with } 5 \%, 10 \% \text { or } 20 \% \text { CIP. } \\
\text { - The selected composite scaffold composed of CS and BG in ratio } 1: 2 \text { loaded } \\
\text { with } 5 \% \text { CIP exhibited satisfactory release rate of Si and good biocompatibility } \\
\text { on Saos-2 cells with promoted cell proliferation and differentiation. }\end{array}$ & {$[46]$} \\
\hline 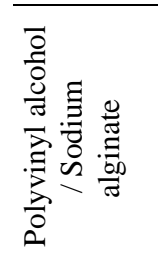 & 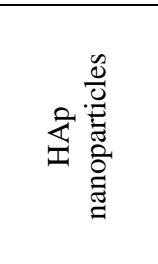 & 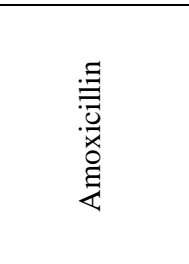 & $\begin{array}{l}\text { - HAp nanoparticles were synthesized by wet precipitation technique. } \\
\text { - The coating of HAp nanoparticles was accomplished by the layer-by-layer } \\
\text { technique. } \\
\text { - Sustainment of amoxicillin release was fulfilled for about } 30 \text { days. } \\
\text { - Agar well diffusion method was used to determine the antibacterial efficacy of } \\
\text { the scaffold against Bacillus subtilis and Klebsiella pneumoniae, showing } \\
\text { optimum activity against these microorganisms. }\end{array}$ & {$[86]$} \\
\hline
\end{tabular}




\begin{tabular}{|c|c|c|c|c|}
\hline Polymer & Ceramic & $\begin{array}{l}\text { Active } \\
\text { moiety }\end{array}$ & Main findings & Reference \\
\hline 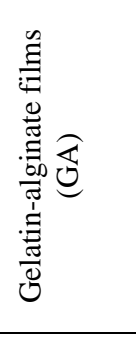 & 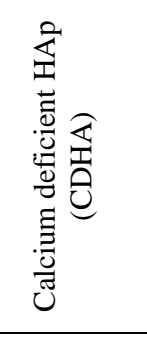 & 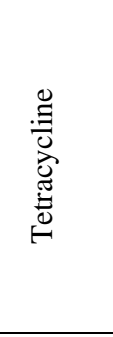 & $\begin{array}{l}\text { - A polymer blend film was prepared by the solvent casting method while } \\
\text { CDHA was prepared by the wet chemical synthesis method. } \\
\text { - Tetracycline was added to polymer blend, CDHA, CDHA polymer solution } \\
\text { and to both CDHA and polymer solution. } \\
\text { - Dividing the drug amount on both CDHA and polymer solution resulted in } \\
\text { sustained release for } 10 \text { days which suits the treatment of periodontal } \\
\text { infections. } \\
\text { - CDHA imparted bioactivity to the composite films render them promising in } \\
\text { the management of periodontal infrabony infections. }\end{array}$ & [87] \\
\hline$\underset{\mho}{\mathbb{a}}$ & 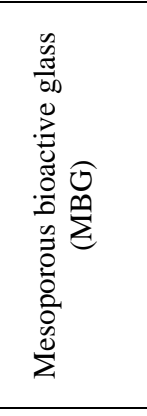 & 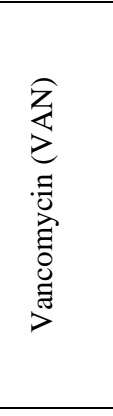 & $\begin{array}{l}\text { - MSG loaded with VAN was combined with PLGA to form composite } \\
\text { scaffolds through the freeze-drying technique. } \\
\text { - The loaded scaffolds showed burst release followed by sustained release of } \\
\text { VAN for about } 8 \text { weeks. } \\
\text { - The in vitro cytocompatibility study on human bone marrow stem cells } \\
\text { (hBMSCs) showed that interconnected porous structure of MBG supported cell } \\
\text { proliferation and adhesion and promoted cell differentiation with elevated } \\
\text { levels of gene expression of ALP, BMP-2, Runx2, and OCN compared to } \\
\text { PLGA scaffolds. } \\
\text { - The loaded composite scaffold showed antibacterial activity and biofilm } \\
\text { inhibiting ability against } S \text {. aureus. }\end{array}$ & {$[88]$} \\
\hline$\frac{\Xi}{\stackrel{\Xi}{0}}$ & $\begin{array}{l}\text { 它 } \\
\text { é }\end{array}$ & 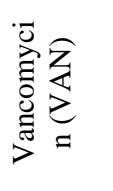 & $\begin{array}{l}\text { - Gelatin porous composite scaffolds were prepared with varying amounts of B- } \\
\text { TCP loaded with VAN for local treatment of OM. } \\
\text { - The selected scaffold showed controlled release of VAN for three weeks and it } \\
\text { shows positive results in bacterial elimination and repairing an osseous defect } \\
\text { in the OM model }\end{array}$ & [89] \\
\hline 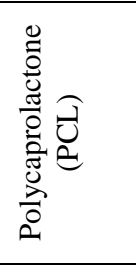 & 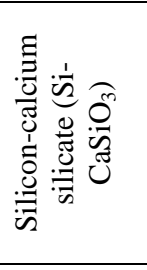 & 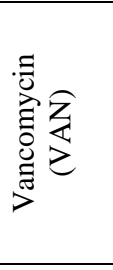 & $\begin{array}{l}\text { - The bioceramic scaffold was fabricated by selective laser melting technique. } \\
\text { - The composite scaffold showed a burst release of } 50 \% \text { of VAN after } 40 \mathrm{~h} \\
\text { followed by a sustained release for } 6 \text { days. } \\
\text { - The bioceramic composites exhibited a controllable porous structure with } \\
\text { about } 35 \% \text { porosity. } \\
\text { - The findings suggest the applicability of their scaffold in competing for S. } \\
\text { aureus infections as in the case of OM. }\end{array}$ & {$[90]$} \\
\hline $\begin{array}{l}\frac{0}{0} \\
\frac{\pi}{2} \\
\frac{\pi}{2}\end{array}$ & 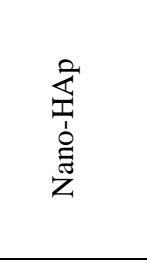 & 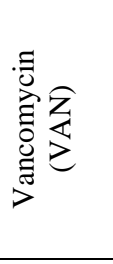 & $\begin{array}{l}\text { - Electrospun PLA/n-HAp/VAN was developed. } \\
\text { - The scaffold exhibited sustained release of VAN and attractive antibacterial } \\
\text { activity against } S \text {. aureus. } \\
\text { - In vitro, cytocompatibility studies showed that the scaffolds enhanced the } \\
\text { adhesion and proliferation of osteoblasts. } \\
\text { - In vivo studies showed favorable outcomes for the scaffolds with a reduction of } \\
\text { infection and enhanced bone repair. }\end{array}$ & {$[91]$} \\
\hline 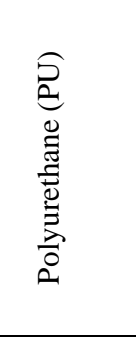 & 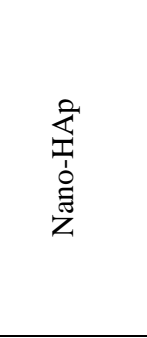 & 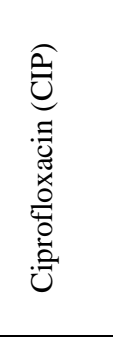 & $\begin{array}{l}\text { - PU-n-HAP/CIP composite scaffolds were developed. } \\
\text { - CIP released from the scaffolds in a sustained manner for at least } 2 \text { weeks. } \\
\text { - The antibacterial activity was determined by measuring the zone of inhibition, } \\
\text { the drug-loaded scaffolds showed good activity against } S \text {. aureus and E. coli. } \\
\text { - The scaffolds capability for promoting proliferation and osteogenic } \\
\text { differentiation was tested using rat-bone-marrow-derived mesenchymal stem } \\
\text { cells (BMSCs), the scaffolds showed positive results on BMSCs. } \\
\text { - The composite scaffolds are a promising model as a pro-osteogenic space } \\
\text { keeper in the treatment of OM. }\end{array}$ & [30] \\
\hline
\end{tabular}




\begin{tabular}{cccc}
\hline Polymer Ceramic & $\begin{array}{l}\text { Active } \\
\text { moiety }\end{array}$ & Main findings \\
\hline &
\end{tabular}

\section{Declarations}

\section{Ethics approval and consent to participate}

Not applicable

\section{Consent to publish}

Not applicable

\section{Availability of data and materials}

All data generated or analyzed during this study are included in this published article in the main manuscript.

\section{Competing interests}

No competing interests were declared by the authors.

\section{Funding Statement}

No funding source was received.

\section{Acknowledgment}

The authors would like to acknowledge all colleagues in the Department of Pharmaceutics and Industrial Pharmacy, Faculty of Pharmacy, Ain Shams University for their continuous support.

\section{Abbreviations}

Alpha and beta-tricalcium phosphate, $\alpha$-TCP and B-TCP; bioactive glass, BG; bone morphogenetic proteins, BMP; calcium deficient hydroxyapatite, CDHA; calcium phosphates, $\mathrm{CP}$; calcium phosphate cements, CPCs; chitosan, CS; ciprofloxacin, CIP; dicalcium phosphate dihydrate brushite, DCPD; extracellular matrix, ECM; gelatin-alginate films, GA; graphine oxide, GO; human bone marrow stem cells, hBMSCs); human fetal osteoblast cells, hFOB; human lactoferrin 1-11, hLF1-11; hydroxyapatite, Hap; levofloxacin, LFH; magnesium phosphate cement, MPC; mesoporous bioactive glass, MBG; monocalcium phosphate, MCP; orthopedic device-related infections (ODRI), osteomyelitis, OM; platelet-rich fibrin, PRF; polymethyl methacrylate, PMMA; polycaprolactone, PCL; poly-lactide, PLA; poly-lactide-co-glycolic, PLGA; polyurethanes, PU; polyvinyl alcohol, PVA; quaternized chitosan, HACC; rifampin (RF) , Staphylococcus (S.), tetracalcium phosphate, TTCP; titanium, Ti; titanium aluminium niobium, TAN; US Food and Drug Administration, FD; vancomycin, VAN. 


\section{REFERENCES}

1. Downey, P.A., Siegel, M.I. Bone biology and the clinical implications for osteoporosis. Phys Ther 2006; 86 (1):77-91. 10.1093/ptj/86.1.77

2. Florencio-Silva, R., Sasso, G.R.d.S., Sasso-Cerri, E., Simões, M.J., Cerri, P.S. Biology of bone tissue: structure, function, and factors that influence bone cells. BioMed research international 2015; 2015

3. Clarke, B. Normal bone anatomy and physiology. Clinical Journal of the American Society of Nephrology 2008; 3 131-139. 10.2215/cjn.04151206

4. Dallas, S.L., Prideaux, M., Bonewald, L.F. The Osteocyte: An Endocrine Cell ... and More. Endocrine Reviews 2013; 34 (5):658-690. 10.1210/er.2012-1026

5. Ralston, S.H. Bone structure and metabolism. Medicine 2013; $41 \quad$ (10):581-585. https://doi.org/10.1016/j.mpmed.2013.07.007

6. Eliaz, N., Metoki, N. Calcium phosphate bioceramics: A review of their history, structure, properties, coating technologies and biomedical applications. Materials (Basel, Switzerland) 2017; 10 (4):334. 10.3390/ma10040334

7. Sarigol-Calamak, E., Hascicek, C. Tissue Scaffolds As a Local Drug Delivery System for Bone Regeneration, in: Chun, H.J., Park, C.H., Kwon, I.K., Khang, G. Cutting-Edge Enabling Technologies for Regenerative Medicine. Singapore,Springer Singapore; 2018, p. 475-493.

8. Zeng, Y., Hoque, J., Varghese, S. Biomaterialassisted local and systemic delivery of bioactive agents for bone repair. Acta Biomater 2019; 93 152-168. https://doi.org/10.1016/j.actbio.2019.01.060

9. Lew, D.P., Waldvogel, F.A. Osteomyelitis. The Lancet 2004; 364 (9431):369-379. 10.1016/s01406736(04)16727-5

10. Jiang, B., Wang, Y., Feng, Z., Xu, L., Tan, L., Zhao, S., Gong, Y., Zhang, C., Luo, X., Li, S., Rao, X., Peng, Y., Xie, Z., Hu, X. PantonValentine Leucocidin (PVL) as a Potential
Indicator for Prevalence, Duration, and Severity of Staphylococcus aureus Osteomyelitis. Frontiers in $\begin{array}{llll}\text { Microbiology } & 2017 ; & 8 & 2355 .\end{array}$ 10.3389/fmicb.2017.02355

11. Chen, P., Yao, Z., Deng, G., Hou, Y., Chen, S., $\mathrm{Hu}, \mathrm{Y} ., \mathrm{Yu}, \mathrm{B}$. Differentially expressed genes in osteomyelitis induced by Staphylococcus aureus infection. Frontiers in Microbiology 2018; 9 (1093):10.3389/fmicb.2018.01093

12. Sweeney, E., Lovering, A.M., Bowker, K.E., MacGowan, A.P., Nelson, S.M. An in vitro biofilm model of Staphylococcus aureus infection of bone. Letters in Applied Microbiology 2019; 68 (4):294302. 10.1111/lam.13131

13. Chihara, S., Segreti, J. Osteomyelitis. Disease-aMonth 2010; $56 \quad$ (1):5-31. 10.1016/j.disamonth.2009.07.001

14. Fantoni, M., Taccari, F., Giovannenze, F. Systemic antibiotic treatment of chronic osteomyelitis in adults. Eur Rev Med Pharmacol Sci 2019; $23 \quad$ (2 Suppl):258-270. 10.26355/eurrev_201904_17500

15. Otto, M. Staphylococcus aureus toxins. Current Opinion in Microbiology 2014; 17 32-37. https://doi.org/10.1016/j.mib.2013.11.004

16. Qiao, Z., Yuan, Z., Zhang, W., Wei, D., Hu, N. Preparation, in vitro release and antibacterial activity evaluation of rifampicin and moxifloxacinloaded poly(D,L-lactide-co-glycolide) microspheres. Artif Cells Nanomed Biotechnol 2019; $47 \quad$ (1):790-798 $10.1080 / 21691401.2019 .1581792$

17. Groll, M.E., Woods, T., Salcido, R. Osteomyelitis: A context for wound management. Advances in Skin \& Wound Care 2018; 31 (6):253-262. 10.1097/01.ASW.0000532737.64628.2a

18. Cierny, G., 3rd. Surgical treatment of osteomyelitis. Plast Reconstr Surg 2011; 127 (1S):190-204. 10.1097/PRS.0b013e3182025070

19. Dudareva, M., Hotchen, A.J., Ferguson, J., Hodgson, S., Scarborough, M., Atkins, B.L., McNally, M.A. The microbiology of chronic osteomyelitis: Changes over ten years. Journal of 
Infection

2019;

https://doi.org/10.1016/j.jinf.2019.07.006

20. Birt, M.C., Anderson, D.W., Bruce Toby, E., Wang, J. Osteomyelitis: Recent advances in pathophysiology and therapeutic strategies. Journal of orthopaedics 2017; $14 \quad$ (1):45-52. 10.1016/j.jor.2016.10.004

21. Schmitt, S.K. Osteomyelitis. Infectious Disease Clinics of North America 2017; 31 (2):325-338. https://doi.org/10.1016/j.idc.2017.01.010

22. Mestres, G., Fernandez-Yague, M.A., Pastorino, D., Montufar, E.B., Canal, C., ManzanaresCéspedes, M.C., Ginebra, M.P. In vivo efficiency of antimicrobial inorganic bone grafts in osteomyelitis treatments. Materials Science and Engineering: $\quad$ C $2019 ; \quad 97 \quad$ 84-95. https://doi.org/10.1016/j.msec.2018.11.064

23. Caplin, J.D., García, A.J. Implantable antimicrobial biomaterials for local drug delivery in bone infection models. Acta Biomater 2019; 93 2-11. https://doi.org/10.1016/j.actbio.2019.01.015

24. Cheng, X., Wei, Q., Ma, Y., Shi, R., Chen, T., Wang, Y., Ma, C., Lu, Y. Antibacterial and osteoinductive biomacromolecules composite electrospun fiber. Int J Biol Macromol 2020; 143 958-967. https://doi.org/10.1016/j.ijbiomac.2019.09.156

25. Wei, J., Wang, Y., Jiang, J., Yan, Y., Fan, D., Yang, X., Zuo, Y., Li, Y., Gu, H., Li, J. Development of an antibacterial bone graft by immobilization of levofloxacin hydrochlorideloaded mesoporous silica microspheres on a porous scaffold surface. J Biomed Nanotechnol 2019; 15 (5):1097-1105. 10.1166/jbn.2019.2743

26. Ford, C.A., Cassat, J.E. Advances in the local and targeted delivery of anti-infective agents for management of osteomyelitis. Expert review of anti-infective therapy 2017; 15 (9):851-860. $10.1080 / 14787210.2017 .1372192$

27. Ferguson, J., Diefenbeck, M., McNally, M. Ceramic biocomposites as biodegradable antibiotic carriers in the treatment of bone infections. Journal of Bone and Joint Infectection 2017; 2 (1):38-51. 10.7150/jbji.17234
28. Stepniewski, M., Martynkiewicz, J., Gosk, J. Chitosan and its composites: Properties for use in bone substitution. Polymers in Medicine 2017; 47 (1):49-53. 10.17219/pim/76517

29. Mishra, R., Varshney, R., Das, N., Sircar, D., Roy, P. Synthesis and characterization of gelatin-PVP polymer composite scaffold for potential application in bone tissue engineering. European Polymer Journal 2019; 119 155-168. https://doi.org/10.1016/j.eurpolymj.2019.07.007

30. Lin, L., Shao, J., Ma, J., Zou, Q., Li, J., Zuo, Y., Yang, F., Li, Y. Development of ciprofloxacin and nano-hydroxyapatite dual-loaded polyurethane scaffolds for simultaneous treatment of bone defects and osteomyelitis. Materials Letters 2019; 253

86-89. https://doi.org/10.1016/j.matlet.2019.06.028

31. Makiishi, J., Matsuno, T., Ito, A., Sogo, Y., Satoh, T. In vitro/in vivo evaluation of the efficacy of gatifloxacine-loaded PLGA and hydroxyapatite composite for treating osteomyelitis. Dent Mater J 2017; 36 (6):714-723. 10.4012/dmj.2016-338

32. Inzana, J.A., Schwarz, E.M., Kates, S.L., Awad, H.A. Biomaterials approaches to treating implantassociated osteomyelitis. Biomaterials 2016; 81 58-71.

https://doi.org/10.1016/j.biomaterials.2015.12.012

33. Makarov, C., Cohen, V., Raz-Pasteur, A., Gotman, I. In vitro elution of vancomycin from biodegradable osteoconductive calcium phosphatepolycaprolactone composite beads for treatment of osteomyelitis. European Journal of Pharmaceutical Sciences $\quad 2014 ; \quad 62 \quad 49-56$. 10.1016/j.ejps.2014.05.008

34. Dorati, R., DeTrizio, A., Modena, T., Conti, B., Benazzo, F., Gastaldi, G., Genta, I. Biodegradable Scaffolds for Bone Regeneration Combined with Drug-Delivery Systems in Osteomyelitis Therapy.

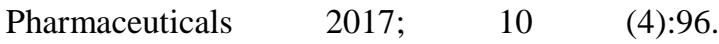
10.3390/ph10040096

35. Wu, J., Xie, L., Lin, W.Z.Y., Chen, Q. Biomimetic nanofibrous scaffolds for neural tissue engineering and drug development. Drug Discovery Today
2017;
22
(9):1375-1384 
https://doi.org/10.1016/j.drudis.2017.03.007

36. Romanò, C., De Vecchi, E., Bortolin, M., Morelli, I., Drago, L. Hyaluronic acid and its composites as a local antimicrobial/antiadhesive barrier. J Bone Jt Infect 2017; 2 (1):63.

37. Pawar, V., Srivastava, R. Chitosanpolycaprolactone blend sponges for management of chronic osteomyelitis: A preliminary characterization and in vitro evaluation. Int $\mathbf{J}$ Pharm 2019; 568 https://doi.org/10.1016/j.ijpharm.2019.118553

38. Manavitehrani, I., Fathi, A., Badr, H., Daly, S., Negahi Shirazi, A., Dehghani, F. Biomedical Applications of Biodegradable Polyesters. Polymers 2016; 8 (1):20.

39. Ueng, S.W., Lin, S.S., Wang, I.C., Yang, C.Y., Cheng, R.C., Liu, S.J., Chan, E.C., Lai, C.F., Yuan, L.J., Chan, S.C. Efficacy of vancomycinreleasing biodegradable poly(lactide-co-glycolide) antibiotics beads for treatment of experimental bone infection due to Staphylococcus aureus. J Orthop Surg Res 2016; 11 (1):52. 10.1186/s13018016-0386-x

40. Chocholata, P., Kulda, V., Babuska, V. Fabrication of scaffolds for bone-tissue regeneration. Materials (Basel, Switzerland) 2019; 12 (4):568. 10.3390/ma12040568

41. Lim, S.S., Kho, S.W., Ang, N.L.H., Pang, C.H., Loh, H.-S. The Influence of Mg2+ Ions on the In Vitro Efficacy of Chitosan-Titanium Dioxide Nanotubes (CTNTs) Scaffolds. Advances in Polymer Technology 2019; $2019 \quad 10$. $10.1155 / 2019 / 9679627$

42. Vallet-Regí, M., Salinas, A.J. Ceramics as bone repair materials, in: Pawelec, K.M., Planell, J.A. Bone Repair Biomaterials second ed,Woodhead Publishing; 2019, p. 141-178.

43. Sasireka, A., Rajendran, R., Priya, P., Raj, V. Ciprofloxacin-Loaded ceramic/polymer composite coatings on $\mathrm{Ti}$ with improved antibacterial and corrosion resistance properties for orthopedic applications. Chemistry Select 2019; 4 (4):11661175. 10.1002/slct.201803769
44. Dasgupta, S., Maji, K., Nandi, S.K. Investigating the mechanical, physiochemical and osteogenic properties in gelatin-chitosan-bioactive nanoceramic composite scaffolds for bone tissue regeneration: In vitro and in vivo. Materials Science and Engineering: C 2019; 94 713-728. https://doi.org/10.1016/j.msec.2018.10.022

45. Pina, S., Rebelo, R., Correlo, V.M., Oliveira, J.M., Reis, R.L. Bioceramics for osteochondral tissue engineering and regeneration, in: Oliveira, J.M., Pina, S., Reis, R.L., San Roman, J. Osteochondral Tissue Engineering: Nanotechnology, ScaffoldingRelated Developments and Translation. Cham,Springer International Publishing; 2018, p. 53-75.

46. Mostafa, A.A., El-Sayed, M.M.H., Mahmoud, A.A., Gamal-Eldeen, A.M. Bioactive/Natural Polymeric Scaffolds Loaded with Ciprofloxacin for Treatment of Osteomyelitis. AAPS PharmSciTech 2017; $18 \quad$ (4):1056-1069. 10.1208/s 12249-016-0605-0

47. Xuan Vuong, B. Evaluating formation and bioactivity of new sol-gel bioactive glass. VNU Journal of Science: Natural Sciences and Technology 2019; 35 (1):68-75. 10.25073/2588$1140 /$ vnunst.4832

48. Turnbull, G., Clarke, J., Picard, F., Riches, P., Jia, L., Han, F., Li, B., Shu, W. 3D bioactive composite scaffolds for bone tissue engineering. Bioactive Materials 2018; 3 (3):278-314. https://doi.org/10.1016/j.bioactmat.2017.10.001

49. Khurshid, Z., Husain, S., Alotaibi, H., Rehman, R., Zafar, M.S., Farooq, I., Khan, A.S. Novel techniques of scaffold fabrication for bioactive glasses, in: Kaur, G. Biomedical, Therapeutic and Clinical Applications of Bioactive Glasses.Woodhead Publishing; 2019, p. 497-519.

50. Kaur, G., Kumar, V., Baino, F., Mauro, J.C., Pickrell, G., Evans, I., Bretcanu, O. Mechanical properties of bioactive glasses, ceramics, glassceramics and composites: State-of-the-art review and future challenges. Materials Science and Engineering: C 2019; $104 \quad 109895$. https://doi.org/10.1016/j.msec.2019.109895 
51. Roberts, T.T., Rosenbaum, A.J. Bone grafts, bone substitutes and orthobiologics: the bridge between basic science and clinical advancements in fracture healing. Organogenesis 2012; 8 (4):114-124. 10.4161/org. 23306

52. Eriwati, Y.K., Utami, D.P., Arsista, D., Sunarso, S., Triaminingsih, S. Characterization of granular calcium sulfate dihydrate-gelatin composite for bone void filler. Key Engineering Materials 2020; 829

69-74.

10.4028/www.scientific.net/KEM.829.69

53. LeGeros, R.Z., LeGeros, J.P. Calcium Phosphate Bioceramics: Past, Present and Future. Key Engineering Materials 2003; 240-242 3-10. 10.4028/www.scientific.net/KEM.240-242.3

54. Xu, H.H.K., Wang, P., Wang, L., Bao, C., Chen, Q., Weir, M.D., Chow, L.C., Zhao, L., Zhou, X., Reynolds, M.A. Calcium phosphate cements for bone engineering and their biological properties. Bone Research 2017; 517056. 10.1038/boneres.2017.56

55. Sergey, V.D. Calcium orthophosphate (CaPO4) scaffolds for bone tissue engineering applications. Journal of Biotechnology and Biomedical Science 2018; 1 (3):25-93. https://doi.org/10.14302/issn.2576-6694.jbbs-18$\underline{2143}$

56. Haugen, H.J., Lyngstadaas, S.P., Rossi, F., Perale, G. Bone grafts: which is the ideal biomaterial? Journal of Clinical Periodontology 2019; 46 (S21):92-102. 10.1111/jcpe.13058

57. Duta, L., Popescu, A.C. Current status on pulsed laser deposition of coatings from animal-origin calcium phosphate sources. Coatings 2019; 9 (5):335.

58. Akin, I., Goller, G. Processing technologies for bioceramic based composites, in: Antoniac, I.V. Handbook of Bioceramics and Biocomposites. Cham,Springer International Publishing; 2016, p. 639-666.

59. Ginebra, M.-P., Canal, C., Espanol, M., Pastorino, D., Montufar, E.B. Calcium phosphate cements as drug delivery materials. Adv Drug Deliv Rev 2012;

64

(12):1090-1110. https://doi.org/10.1016/j.addr.2012.01.008

60. Qu, S., Weng, J., Duan, K., Liu, Y. Drug-loading calcium phosphate cements for medical applications, in: Liu, C., He, H. Developments and Applications of Calcium Phosphate Bone Cements. Singapore,Springer Singapore; 2018, p. 299-332.

61. Joosten, U., Joist, A., Frebel, T., Brandt, B., Diederichs, S., von Eiff, C. Evaluation of an in situ setting injectable calcium phosphate as a new carrier material for gentamicin in the treatment of chronic osteomyelitis: Studies in vitro and in vivo. Biomaterials 2004; 25 (18):4287-4295. https://doi.org/10.1016/j.biomaterials.2003.10.083

62. Stallmann, H.P., Faber, C., Bronckers, A.L.J.J., Nieuw Amerongen, A.V., Wuisman, P.I.J.M. Osteomyelitis prevention in rabbits using antimicrobial peptide hLF1-11- or gentamicincontaining calcium phosphate cement. Journal of Antimicrobial Chemotherapy 2004; 54 (2):472476. 10.1093/jac/dkh346

63. Huang, J.-G., Pang, L., Chen, Z.-R., Tan, X.-P. Dual-delivery of vancomycin and icariin from an injectable calcium phosphate cement-release system for controlling infection and improving bone healing. Molecular medicine reports 2013; 8 (4):1221-1227.

64. Thompson, K., Petkov, S., Zeiter, S., Sprecher, C.M., Richards, R.G., Moriarty, T.F., Eijer, H. Intraoperative loading of calcium phosphatecoated implants with gentamicin prevents experimental Staphylococcus aureus infection in vivo. PLOS ONE 2019; 14 (2):e0210402. 10.1371/journal.pone.0210402

65. Stigter, M., Bezemer, J., de Groot, K., Layrolle, P. Incorporation of different antibiotics into carbonated hydroxyapatite coatings on titanium implants, release and antibiotic efficacy. Journal of Controlled Release 2004; 99 (1):127-137. https://doi.org/10.1016/j.jconrel.2004.06.011

66. Neut, D., Dijkstra, R.J.B., Thompson, J.I., Kavanagh, C., van der Mei, H.C., Busscher, H.J. A biodegradable gentamicin-hydroxyapatite-coating for infection prophylaxis in cementless hip prostheses. European Cells and Materials 2015; 29 


\section{2-56. 10.22203/eCM.v029a04}

67. Kranthi Kiran, A.S., Kizhakeyil, A., Ramalingam, R., Verma, N.K., Lakshminarayanan, R., Kumar, T.S.S., Doble, M., Ramakrishna, S. Drug loaded electrospun polymer/ceramic composite nanofibrous coatings on titanium for implant related infections. Ceramics International 2019; 45 (15):18710-18720. https://doi.org/10.1016/j.ceramint.2019.06.097

68. Bai, X., Gao, M., Syed, S., Zhuang, J., Xu, X., Zhang, X.-Q. Bioactive hydrogels for bone regeneration. Bioactive Materials 2018; 3 (4):401417. 10.1016/j.bioactmat.2018.05.006

69. Posadowska, U., Brzychczy-Wloch, M., Drozdz, A., Krok-Borkowicz, M., Wlodarczyk-Biegun, M., Dobrzynski, P., Chrzanowski, W., Pamula, E. Injectable hybrid delivery system composed of gellan gum, nanoparticles and gentamicin for the localized treatment of bone infections. Expert Opin Drug Deliv 2016; 13 (5):613-620. 10.1517/17425247.2016.1146673

70. Wu, G., Feng, C., Quan, J., Wang, Z., Wei, W., Zang, S., Kang, S., Hui, G., Chen, X., Wang, Q. In situ controlled release of stromal cell-derived factor- $1 \alpha$ and antimiR-138 for on-demand cranial bone regeneration. Carbohydrate Polymers 2018; 182

215-224.

https://doi.org/10.1016/j.carbpol.2017.10.090

71. Zheng, L., Wang, L., Qin, J., Sun, X., Yang, T., Ni, Y., Zhou, Y. New biodegradable implant material containing hydrogel with growth factors of lyophilized PRF in combination with an nHA/PLGA scaffold. Journal of Hard Tissue Biology 2015; 24 (1):54-60.

72. Dhivya, S., Saravanan, S., Sastry, T.P., Selvamurugan, N. Nanohydroxyapatite-reinforced chitosan composite hydrogel for bone tissue repair in vitro and in vivo. Journal of Nanobiotechnology 2015; 13 (1):40. 10.1186/s12951-015-0099-Z

73. Piantanida, E., Alonci, G., Bertucci, A., De Cola, L. Design of nanocomposite injectable hydrogels for minimally invasive surgery. Acc Chem Res 2019; $\quad 52 \quad$ (8):2101-2112. 10.1021/acs.accounts.9b00114
74. Gao, C., Deng, Y., Feng, P., Mao, Z., Li, P., Yang, B., Deng, J., Cao, Y., Shuai, C., Peng, S. Current progress in bioactive ceramic scaffolds for bone repair and regeneration. International Journal of Molecular Sciences 2014; 15 (3):4714-4732.

75. Webber, M.J., Khan, O.F., Sydlik, S.A., Tang, B.C., Langer, R. A Perspective on the clinical translation of scaffolds for tissue engineering. Annals of Biomedical Engineering 2015; 43 (3):641-656. 10.1007/s10439-014-1104-7

76. Kankilic, B., Bayramli, E., Kilic, E., Dagdeviren, S., Korkusuz, F. Vancomycin containing PLLA/beta-TCP controls MRSA in vitro. Clinical Orthopaedics and Related Research 2011; 469 (11):3222-3228. 10.1007/s11999-011-2082-9

77. Yan, L., Jiang, D.-M., Cao, Z.-D., Wu, J., Wang, X., Wang, Z.-L., Li, Y.-J., Yi, Y.-F. Treatment of Staphylococcus aureus-induced chronic osteomyelitis with bone-like hydroxyapatite/poly amino acid loaded with rifapentine microspheres. Drug design, development and therapy 2015; 9 3665-3676. 10.2147/DDDT.S84486

78. Kimishima, K., Matsuno, T., Makiishi, J., Tamazawa, G., Sogo, Y., Ito, A., Satoh, T. Effects of gatifloxaine content in gatifloxacine-loaded PLGA and beta-tricalcium phosphate composites on efficacy in treating osteomyelitis. Odontology 2016; 104 (1):105-113. 10.1007/s10266-014-01879

79. Yang, Y., Yang, S., Wang, Y., Yu, Z., Ao, H., Zhang, H., Qin, L., Guillaume, O., Eglin, D., Richards, R.G., Tang, T. Anti-infective efficacy, cytocompatibility and biocompatibility of a 3Dprinted osteoconductive composite scaffold functionalized with quaternized chitosan. Acta Biomater 2016; $46 \quad$ 112-128. https://doi.org/10.1016/j.actbio.2016.09.035

80. Yang, Y., Chu, L., Yang, S., Zhang, H., Qin, L., Guillaume, O., Eglin, D., Richards, R.G., Tang, T. Dual-functional 3D-printed composite scaffold for inhibiting bacterial infection and promoting bone regeneration in infected bone defect models. Acta Biomater 2018; 79 265-275. https://doi.org/10.1016/j.actbio.2018.08.015 
81. García-Alvarez, R., Izquierdo-Barba, I., ValletRegí, M. 3D scaffold with effective multidrug sequential release against bacteria biofilm. Acta Biomater 2017; 49 113-126. https://doi.org/10.1016/j.actbio.2016.11.028

82. Seidenstuecker, M., Ruehe, J., Suedkamp, N.P., Serr, A., Wittmer, A., Bohner, M., Bernstein, A., Mayr, H.O. Composite material consisting of microporous $\beta$-TCP ceramic and alginate for delayed release of antibiotics. Acta Biomater 2017; 51 433-446. https://doi.org/10.1016/j.actbio.2017.01.045

83. Zhang, Y., Zhai, D., Xu, M., Yao, Q., Zhu, H., Chang, J., Wu, C. 3D-printed bioceramic scaffolds with antibacterial and osteogenic activity. Biofabrication 2017; 9 (2):25-37.

84. Dubnika, A., Loca, D., Rudovica, V., Parekh, M.B., Berzina-Cimdina, L. Functionalized silver doped hydroxyapatite scaffolds for controlled simultaneous silver ion and drug delivery. Ceramics International 2017; 43 (4):3698-3705. https://doi.org/10.1016/j.ceramint.2016.11.214

85. Channasanon, S., Udomkusonsri, P., Chantaweroad, S., Tesavibul, P., Tanodekaew, S. Gentamicin released from porous scaffolds fabricated by stereolithography. Journal of Healthcare Engineering 2017; 20178. 10.1155/2017/9547896

86. Prasanna, A.P.S., Venkatasubbu, G.D. Sustained release of amoxicillin from hydroxyapatite nanocomposite for bone infections. Prog Biomater 2018; 7 (4):289-296. 10.1007/s40204-018-0103-4

87. Madhumathi, K., Jeevana Rekha, L., Sampath Kumar, T.S. Tailoring antibiotic release for the treatment of periodontal infrabony defects using bioactive gelatin-alginate/apatite nanocomposite films. Journal of Drug Delivery Science and Technology 2018; $43 \quad$ 57-64. https://doi.org/10.1016/j.jddst.2017.09.015

88. Cheng, T., Qu, H., Zhang, G., Zhang, X. Osteogenic and antibacterial properties of vancomycin-laden mesoporous bioglass/PLGA composite scaffolds for bone regeneration in infected bone defects. Artif Cells Nanomed
Biotechnol 2018; $46 \quad$ (8):1935-1947. 10.1080/21691401.2017.1396997

89. Zhou, J., Zhou, X.G., Wang, J.W., Zhou, H., Dong, J. Treatment of osteomyelitis defects by a vancomycin-loaded gelatin/ $\beta$-tricalcium phosphate composite scaffold. Bone \& joint research 2018; 7 (1):46-57. 10.1302/2046-3758.71.BJR-20170129.R2

90. Kamboj, N., Rodriguez, M., Rahmani Ahranjani, R., K G, P., Hussainova, I. Bioceramic scaffolds by additive manufacturing for controlled delivery of the antibiotic vancomycin. Proceedings of the Estonian Academy of Sciences 2019; 68 (2):185190. 10.3176/proc.2019.2.10

91. Zhao, X., Han, Y., Zhu, T., Feng, N., Sun, Y., Song, Z., Li, S., Liu, J., Ding, J. Electrospun polylactide-nano-hydroxyapatite vancomycin composite scaffolds for advanced osteomyelitis therapy. J Biomed Nanotechnol 2019; 15 (6):12131222. 10.1166/jbn.2019.2773

92. Zhang, D., Liu, W., Wu, X.-D., He, X., Lin, X., Wang, H., Li, J., Jiang, J., Huang, W. Efficacy of novel nano-hydroxyapatite/polyurethane composite scaffolds with silver phosphate particles in chronic osteomyelitis. Journal of Materials Science: Materials in Medicine 2019; 30 (6):59. 10.1007/s10856-019-6261-7

93. Yong, X.H., Mazlam, M.I., Ahmad, N. Fabrication and characterization of porous biphasic $\beta$ tricalcium phosphate/carbonate apatite alginate coated scaffolds. Ceramics International 2018; 44 (8):9499-9505. https://doi.org/10.1016/j.ceramint.2018.02.168 